\title{
PROVOQUE - Problematizando Visualidades e Questionando Estereótipos: leitura de imagens fundamentada nos Estudos da Cultura Visual
}

\section{PROVOQUE - Problematizing Visualities and Questioning Stereotypes: Reading of images based on Visual Culture Studies}

\author{
João Paulo Baliscei*
}

\begin{abstract}
RESUMO
Nas práticas escolares de ensino de Arte, é comum identificar exercícios de leitura de imagem fundamentados em abordagens a partir das quais priorizam-se os elementos formais e plásticos de uma composição. Apesar das contribuições que tais abordagens têm conferido às maneiras como os sujeitos aprendem a se relacionar com as imagens à sua volta, os Estudos da Cultura Visual têm destacado a necessidade de desenvolver maneiras mais críticas e inventivas de ensinar a ler imagens, sobretudo, em contextos em que estereótipos são reforçados pelas visualidades. Nosso objetivo é, portanto, apresentar um conjunto de procedimentos que orientam investigações visuais críticas e inventivas e que dão ênfase aos estereótipos. Denominado de PROVOQUE - uma abreviação para Problematizando Visualidades e Questionando Estereótipos -, esse conjunto de procedimentos tem como fundamentação os Estudos da Cultura Visual e é constituído por cinco etapas. Flertando, Percebendo, Estranhando, Dialogando e Compartilhando oferecem ações analíticas distintas para que imagens estereotipadas sejam analisadas em situações de ensino e pesquisa. Consideramos que o PROVOQUE demonstra que as aproximações estabelecidas com os artefatos visuais não são meramente passivas, mas, sim, críticas e inventivas.
\end{abstract}

Palavras-chave: Educação. Ensino de Arte. Análise de Imagens. Prática de Ensino. Visualidade.

*Universidade Estadual de Maringá. Maringá, Paraná, Brasil. E-mail: jpbaliscei@uem.br. https://orcid.org/0000-0001-8752-244X. 


\begin{abstract}
In school art teaching practices, it is common to identify image reading exercises based on approaches from which the formal and plastic elements of a composition are prioritized. Despite the contributions that such an approach has given to the ways in which subjects learn to relate to images around them, the Visual Culture Studies have highlighted the need to develop more critical and inventive ways of teaching how to read images, especially in contexts where stereotypes are reinforced by visuals. Our objective is, therefore, to present a set of procedures that guide critical and inventive visual investigations and emphasize stereotypes. Denoted as PROVOQUE - an abbreviation for Problematizing Visuals and Questioning Stereotypes -, this set of procedures is based on the Studies of Visual Culture and is constituted by five stages. Flirting (Flertando), Realizing (Percebendo), Wondering (Estranhando), Talking (Dialogando) and Sharing (Compartilhando) offer distinct analytical actions so that stereotyped images are analyzed in teaching and research situations. We consider that PROVOQUE demonstrates that the established approaches to visual artifacts are not merely passive, but rather critical and inventive.
\end{abstract}

Keywords: Education. Art Teaching. Image Analysis. Educational Practice. Visuality.

\title{
Me ensina a olhar?
}

"Diego não conhecia o mar. O pai, Santiago Kovakloff, levou-o para que descobrisse o mar. Viajaram para o Sul.

Ele, o mar, estava do outro lado das dunas altas, esperando.

Quando o menino e o pai enfim alcançaram aquelas alturas de areia, depois de muito caminhar, o mar estava na frente de seus olhos. E foi tanta a imensidão do mar, e tanto seu fulgor, que o menino ficou mudo de beleza. E quando finalmente conseguiu falar, tremendo, gaguejando, pediu ao pai: - Pai, me ensina a olhar!" (A Função da arte/1, Eduardo Galeano).

Os versos elaborados pelo escritor uruguaio Eduardo Galeano (1940-2015) motivam-nos a tomar o olhar como uma construção sociocultural que necessita de mediação para ser ensinada e aprendida. Ao solicitar ao seu pai que o ajude a olhar o mar, Diego - personagem do texto A Função da arte/1 (GALEANO, 
2016) - demonstra que a ação de ver não é composta e dependente apenas da anatomia e fisiologia da visão. Logo, ver e enxergar não são ações concebidas apenas pela constituição biológica. Além do conjunto sensorial do aparelho visual - constituído pela pupila, íris, córnea, cristalino e demais componentes -, outros fatores, dentre eles os educativos e os culturais, interferem nas maneiras como percebemos ou não as imagens ao nosso redor. Por que Diego precisava de ajuda para olhar o mar? O que o impedia de olhá-lo sozinho? O que busca em seu pai?

Diante de algo complexo e nunca antes visto, como o mar para Diego no texto de Galeano (2016), é de se esperar que uma criança não saiba para onde e nem como olhar, e que necessite da orientação e mediação de um/a adulto/a cuja sensibilidade e crítica visual, por hipótese, são aguçadas. Além do mar, quais e quantas são as imagens que passam despercebidas aos nossos olhos e à nossa crítica visual? Pensando em ensinar a olhar, pesquisadores/as e professores/as de Arte têm se movimentado para a criação e experimentação de estratégias de Leitura de Imagens - termo que passou a ser adotado na segunda metade do século XX, incialmente por Rudolf Arnheim (1989) e Donis A. Dondis (1997).

Em comum, os exercícios de leitura de imagens propostos pelo autor e autora dão ênfase à composição gráfico-visual. Para essa abordagem, ler imagens implica observá-las e conhecê-las, decodificando seus aspectos plásticos e os componentes da linguagem visual que as instituem. Pelas características que envolvem essas propostas de leitura de imagens, Maria Emília Sardelich (2006) se refere a elas como Abordagem Formalista, já que tomam os elementos plásticos como categorias analíticas de uma imagem. Dondis (1997, p. 51), por exemplo, argumenta que ponto, linha, contorno, direção, tom, cor, textura, dimensão, escala e movimento são os dez elementos que constituem “[...] a substância básica daquilo que vemos [...] são a matéria-prima de toda a informação visual em termos de opções e combinações seletivas".

Em território brasileiro, Ana Mae Barbosa (1998) e Lúcia Santaella (2012) contribuíram para a divulgação das propostas de Arnheim (1989) e Dondis (1997) desenvolvendo pressupostos teórico-metodológicos para o ensino de Arte onde, até então, predominava a prática de atelier. Santaella (2012), especificamente, propõe que professores e professoras precisam agir em prol do desenvolvimento da alfabetização visual por meio de exercícios de análise dos componentes da linguagem visual. A concepção de alfabetização visual adotada pela autora é caracterizada como sendo aquela que envolve,

[...] aprender a ler imagens, desenvolver a observação de seus aspectos e traços constitutivos, detectar o que se produz no interior da própria 
imagem, sem fugir para outros pensamentos que nada têm a ver com ela. Ou seja, significa adquirir os conhecimentos correspondentes e desenvolver a sensibilidade necessária para saber como as imagens se apresentam, como indicam o que querem indicar, qual é o seu contexto de referência, como as imagens significam, como elas pensam, quais são seus modos específicos de representar a realidade (SANTAELLA, 2012, p. 13, grifos nossos).

Os grifos feitos por nós destacam termos, frases e verbos que indicam que a abordagem formalista parece atribuir mais autonomia às imagens lidas do que aos indivíduos que as leem. Os grifos parecem indicar que as interpretações visuais são mais delimitadas pelas próprias imagens ou por quem as criou do que significadas por aqueles e aquelas que com elas interagem. Apesar das contribuições que tal abordagem tem conferido às maneiras como os sujeitos aprendem a se relacionar com as imagens à sua volta, pesquisas vinculadas aos Estudos da Cultura Visual têm destacado a necessidade de desenvolvermos maneiras mais críticas e complexas de ensinar a ler imagens, como mostram Fernando Hernández (2007) e Leonardo Charréu (2011).

Como trama teórico-metodológica vinculada aos Estudos Culturais, aos Estudos Feministas, à História da Arte e à epistemologia Pós-Moderna, os Estudos da Cultura Visual investigam as maneiras como os sujeitos veem e são vistos pelos artefatos visuais. Consideram, pois, que as relações entre imagens e sujeitos são menos caracterizadas pela suposta "transmissão" de conteúdos por parte das primeiras, e mais pela criação de significados por parte dos segundos. Logo, nessa linha de raciocínio, ao invés de "lerem" significados previamente estabelecidos nas imagens, os sujeitos desempenhariam papéis de Construtores ou Intérpretes Visuais, como propõe Hernández (2007). Os substantivos “construtores" e "intérpretes" indicam que as aproximações estabelecidas com os artefatos visuais não são meramente passivas, mas, sim, interativas, transitórias, mútuas e dinâmicas.

Tendo em vista o caráter ativo e performático que os Estudos da Cultura Visual conferem aos sujeitos em sua interação com as imagens, em nossos estudos (BALISCEI, 2018), temos optado por utilizar a expressão investigações visuais críticas e inventivas para se referir a esse processo de atribuir significados às imagens. $\mathrm{O}$ conceito de investigações visuais críticas e inventivas supõe que os olhares construídos pelos/as intérpretes visuais carregam experiências, valores e imaginários de uma determinada sociedade, cultura e tempo. Isso significa que uma leitura de imagem nunca é apenas uma "leitura" ou uma "extração" de códigos, mas, sim, uma investigação marcada pela criticidade e inventividade. 
Ao investigarmos visualmente, criamos significados. Assim, a prática de investigação visual crítica e inventiva pode ser aproximada da explicação de Analice Dutra Pillar (2011, p. 12), de que a maneira como interagimos com imagens “[...] depende do que está em frente e atrás dos nossos olhos". Nessa analogia estabelecida pela autora, o que está em frente dos nossos olhos seriam as informações oferecidas pelas imagens, e o que está atrás deles seriam os conhecimentos e referências que possuímos, isto é, nosso repertório visual. Também Raimundo Martins e Irene Tourinho (2011, p. 53) se harmonizam com esse pensamento ao afirmarem que a interpretação é "[...] uma prática de produção de significado que depende do ponto de vista do observador/espectador em termos de classe, gênero, etnia, crença, informação e experiência cultural".

Apesar da ênfase que temos dado até aqui à participação ativa dos sujeitos em suas interações com as imagens, em contextos escolares ainda há a predominância de atividades fundamentadas em abordagens com caráter formalista, como aponta Leonardo Charréu (2011). O autor exemplifica que os pressupostos teórico-metodológicos de tais abordagens têm se manifestado no ensino de Arte, dentre outras atividades, na organização de painéis estético-decorativos, cujas formas, cores e repetições acabam por "preencher" o espaço físico da escola e produzir um impacto visual que satisfaz mais docentes e gestores/as do que expressa conhecimentos dos e das estudantes. $\mathrm{O}$ autor chama a atenção para os contextos contemporâneos de intensa produção, circulação e manipulação visual, e a partir dos quais se torna no mínimo inapropriado reduzir o ensino de Arte unicamente a um viés formalista.

Conteúdos como "Comunicação", "Espaço", "Estrutura", "Forma" e "Luz-cor" são os elementos-chave de uma intencionalidade educativa que tinha como finalidade o exercício de uma habilidade formal, numa crença semiótica, hoje com pouco sentido, segundo a qual a arte não seria mais do que exclusivamente uma forma de linguagem, mediadora de coisas externas ao indivíduo, que a tinha que entesourar (musealizar) sempre que alguma obra atingisse um grau de perfeccionismo validado pela História, Teoria e Crítica "tradicionais" da Arte (CHARRÉU, 2011, p. 118).

Explorar as diferentes estratégias e critérios de leitura de imagens para além daqueles valorizados pela abordagem formalista é também uma preocupação de Sardelich (2006, p. 457) que sublinha que ler uma imagem "[...] é mais do que apreciar o seu esqueleto aparente" já que, como artefato produzido, faz circular discursos específicos. Como alternativa às leituras de imagem da abordagem 
formalista, a autora sugere outras maneiras de se relacionar com as imagens de modo a questionar os discursos que elas evidenciam e os modos como os indivíduos as significam. No âmbito do ensino de Arte, sugere aos/às docentes, por exemplo, que problematizem,

[...] as representações sociais de menina, menino, mulher, homem, família, criança, adolescente, adulto, velho, pobre, rico, preto, branco, professor/a, estudante, escola, entre tantas outras possíveis, nas imagens dos livros didáticos, dos cadernos, nas revistas, dos outdoors, dos videojogos, da televisão, dos cartões postais, dos brinquedos, das obras de arte etc. (SARDELICH, 2006, p. 468).

Mesmo levando em conta os avanços conquistados pela abordagem formalista no que diz respeito ao desenvolvimento de metodologias para o ensino de Arte, compartilhamos do ponto de vista dos Estudos da Cultura Visual de que é necessário repensar a prática de leitura de imagens, principalmente, se levarmos em conta as condições pós-modernas nas quais as crianças, jovens e a própria escola estão inseridos.

É preciso considerar que, além dos aspectos formais e estéticos, uma imagem é constituída por representações e discursos que insistem em (re)posicionar indivíduos em situações assimétricas entre si. Conferem autenticidade a certos grupos sociais enquanto representam grupos não-hegemônicos - tais como: mulheres, negros/as e homossexuais - com formas e comportamento estereotipados, reduzindo-os a um conjunto de características depreciativas. A partir de nossa identificação com os Estudos da Cultura Visual, em nossa trajetória científica temos nos debruçado sobre artefatos visuais - tais como propagandas, cadernos universitários e filmes de animação - para investigar, por exemplo, como as imagens contribuem para a legitimação de estereótipos de casais (BALISCEI; ACCORSI; TERUYA, 2017), de feminilidades (BALISCEI; SILVA; CALSA, 2018) e de masculinidades (BALISCEI; CALSA, 2019), respectivamente.

No campo das Artes Visuais, o termo "estereotipado" é utilizado para caracterizar imagens e desenhos pouco complexos, cujos traços, cores e formas guardam relações com modelos copiados, como explicam Ana Angélica Albano Moreira (2008) e Maria Letícia Rauen Vianna (2010)ํ. Papel carbono, mimeógrafo, folha de seda, computadores, impressora e fotocopiadora são alguns dos

1 Após caracterizarem o estereótipo, as autoras passam a se referir a eles como Desenho Pedagógico e Desenho Recebido, respectivamente. 
aparatos que facilitam a reprodução de desenhos estereotipados em contextos escolares e, desta forma - seja pelo conforto que proporcionam ou pela funcionalidade pedagógica que recebem -, configuram parte das ações desempenhadas por professoras e professores durante o ensino de Arte.

Pela uniformidade dos traços, cores e formas da estereotipia, Moreira (2008) e Vianna (2010) concordam que os desenhos estereotipados não são expressões de quem desenha, mas, sim, valorizam uma espécie de poética própria, cuja autoria e origem a sociedade como um todo desconhece. Alexandre Adalberto Pereira (2010, p. 214-215) caracteriza a "poética" dos desenhos estereotipados escolares da seguinte forma:

Figuras que são apresentadas como modelos que sugerem um contorno, um sentido de mundo infantilizado; figuras cuja aparência é sempre arredondada, desbastada, polida, sem incômodas arestas; onde os personagens que habitam este universo fictício são criaturas delicadas e dóceis, e estão sempre sorrindo; atentos com seus olhares graúdos dialogando conosco, fitando-nos diretamente, com o rosto solícito e expressão acolhedora; são figuras que agradam aos alunos e professores, suavizam o ambiente escolar, disfarçam com alegria a obrigatoriedade desconfortável das tarefas escolares e, sobretudo, medeiam aprendizados.

O significado que hoje atribuímos a esses desenhos escolares tem a ver, conforme Vianna (2010), com uma técnica de impressão chamada estereotipia, cuja origem não se têm consenso ${ }^{2}$. Com o passar do tempo, os termos estereótipo e estereotipia, enquanto processos de impressão, receberam outras significações e começaram a ser utilizados como predicativos de alguém ou de alguma coisa que é sempre repetida, sem alterações.

Pela potencialidade assinalada em sua origem etimológica, os estereótipos - do grego, stereos (sólido) e typos (impressão) - são criados para serem lidos com rigor e superficialidade e, com isso, provocam fixações identitárias, como argumenta Tomaz Tadeu da Silva (2006). Semelhante ao processo de impressão que utilizava de uma matriz fixa para cópias exatas ao molde e aos desenhos estereotipados escolares, os estereótipos divulgados nas imagens da cultura da mídia valorizam a reprodução de identidades pouco complexas. Por meio de imagens óbvias - tais como as de negros/as dançando e jogando

2 Conforme Vianna (2010) muitos/as atribuem sua criação a Bi Sheng (1041-1049), um chinês que utilizava moldes de argila para impressão, e outros ao tipógrafo francês Firmin Didot (1764-1836). 
basquete ou de meninas brincando com bonecas e utensílios domésticos, como denunciam Shirley Steinberg e Joe Kincheloe (2001) -, essas representações visuais simplificam as diferenças, ajustando-as conforme os valores, estéticas e interesses hegemônicos.

$\mathrm{O}$ interesse que temos demonstrado por produzir atravessamentos a esses estereótipos consolidados pelos e nos artefatos visuais posiciona tais imagens como sendo o avesso da diferença, do aprofundamento e do multicultural. Se as condições pós-modernas possibilitam novas maneiras de produzir imagens, neste artigo, nossa proposição - como talvez tenha transparecido desde a escolha da epígrafe - é investigar novas maneiras de ler imagens. Nosso objetivo é, portanto, apresentar um conjunto de procedimentos que orientam investigações visuais críticas e inventivas que dão ênfase aos estereótipos. Denominado de PROVOQUE - uma abreviação para Problematizando Visualidades e Questionando Estereótipos -, esse conjunto de procedimentos tem como fundamentação os estudos da Cultura Visual, e foi inspirado no Image Watching ${ }^{3}$ e na Abordagem Triangular ${ }^{4}$. Como sistematização metodológica que orienta investigações visuais críticas e inventivas com ênfase nos estereótipos, as cinco etapas que integram o PROVOQUE sugerem ações analíticas específicas para docentes, pesquisadores/as, alunos/as e demais sujeitos que, assim como Diego - o personagem do texto de Galeano -, tenham curiosidade por aprender a olhar.

\section{PROVOQUE: Problematizando Visualidades e Questionando Estereótipos}

Hernández (2007, p. 29) argumenta que, ainda “[...] que haja muita produção sobre as questões visuais, não há quase formulações sobre métodos de interpretação e de como usar estes métodos, nem para a pesquisa, nem para a educação". Nesse sentido, o PROVOQUE pode operar tanto como procedimento de investigações visuais críticas e inventivas para a pesquisa científica quanto para

3 Trata-se de um sistema de análise de imagem criado por Robert William Ott (2011), constituído por cinco etapas (Descrevendo, Analisando, Interpretando, Fundamentando e Revelando) que, por sua vez, são precedidas de um momento de aquecimento denominada Thought Watching. Incialmente, fora aplicado em museus estadunidenses e, com o passar do tempo, foi conhecido e adaptado em outros países, como o Brasil.

4 Sistematização didática criada por Ana Mae Barbosa (1998) e integrada por três eixos: Fazer Artístico, Leitura e Contextualização. Fora praticada inicialmente no Museu de Arte Contemporânea da Universidade de São Paulo (MAC-USP) entre 1987 e 1993. A partir de 1989, passou a ser experimentada também em salas de aulas, com as crianças das escolas municipais de São Paulo. 
o ensino. Dito de outra forma, pode orientar tanto as análises realizadas por professores/as quanto aquelas realizadas por pesquisadores/as, auxiliando-os/as na sistematização de seus estudos e na apresentação dos resultados a que chegaram.

Investigar artefatos visuais crítica e inventivamente tem sido uma das preocupações salientadas, em nossas vivências com o doutorado em Educação (BALISCEI, 2018), e intensificadas durante nossas ações junto aos acadêmicos e acadêmicas de Artes Visuais e de Pedagogia, nas orientações de Trabalho de Conclusão de Curso e também - e não menos importante - em conversas despretensiosas em museus, cafés, bares, cinemas, jantares e rodas de conversa.

Em alguns casos, esses exercícios de leitura de imagem foram sistematizados em artigos e posteriormente publicados em revistas científicas (BALISCEI; ACCORSI; TERUYA, 2017; BALISCEI; SILVA; CALSA, 2018; BALISCEI; CALSA, 2019) - elaboração essa que foi de fundamental importância para a sistematização do PROVOQUE. A seleção dos artefatos visuais analisados, os procedimentos e critérios analíticos adotados, os erros e acertos e as estratégias de exposição dos dados que experimentamos nesses estudos com nossos pares atuaram como uma espécie de "laboratório" para o PROVOQUE, contribuindo para a formulação e reformulação de suas cinco etapas.

Apresentadas no gerúndio - tempo verbal que reitera ação continuada - as cinco etapas do PROVOQUE são: Flertando, Percebendo, Estranhando, Dialogando e Compartilhando. Individual e coletivamente, orientam ações específicas que contribuem para a realização de investigações visuais críticas e inventivas.

\section{Flertando, Percebendo, Estranhando, Dialogando e Compartilhando}

Flertar - o verbo que dá nome à primeira etapa do PROVOQUE - é sinônimo de paquerar, de cortejar, e indica interesse e paixão por algo. Ao mesmo tempo, sugere uma aproximação sem obrigações previamente estabelecidas ou, no mínimo, descompromissada. Em Flertando, assistimos a filmes, peças publicitárias, desenhos animados e novelas; atentamo-nos a cartazes, embalagens de produtos e brinquedos; ouvimos músicas, debruçamo-nos sobre os aspectos identitários de suas letras, ritmos e passinhos, etc. Com esses exemplos, esclarecemos que a etapa Flertando possibilita e incentiva escolher qualquer imagem dentro de uma gama de visualidades possíveis: bidimensionais, tridimensionais ou virtuais; longínquas ou contemporâneas; pintadas, fotografadas ou esculpidas; móveis ou estáticas. 
Por levar em conta as maneiras como os indivíduos são significados e significam as imagens, essa etapa envolve aspectos subjetivos e pessoais e proporciona a ampliação dos objetos investigados para aqueles considerados "eruditos". Tal orientação vai ao encontro da sugestão de Hernández (2007) quando recomenda aos/às intérpretes visuais que se aproximem dos espaços frequentados e valorizados pelos sujeitos infantis - tais como shopping center, cinemas, praças e lan houses - a fim de acompanharem, perceberem e analisarem, as maneiras como crianças e jovens se relacionam com e a partir dos artefatos da Cultura Visual.

Essa etapa é composta por duas ações analíticas: a composição do corpus de análise (formado por uma ou mais imagens) e a exposição dos critérios adotados para essa seleção. Para a primeira ação, sugerimos a escolha de imagens que: a) excitem o debate e a exposição de opiniões; b) provoquem incômodos, desequilíbrios e estranhamentos; c) integrem a cultura da mídia, sendo populares e acessíveis aos indivíduos; d) (re)produzam estereótipos; e e) ou, ainda, que promovam questionamentos e desestabilizações das representações convencionais contidas nos estereótipos. Quanto à segunda ação analítica - exposição dos critérios adotados -, caso haja imagens previamente selecionadas, podem ser relatados os motivos dessa escolha; caso as imagens sejam selecionadas posteriormente, os/as intérpretes visuais podem justificar suas decisões de descarte e seleção expondo os critérios utilizados para a composição do corpus de análise.

Na segunda etapa, Percebendo, o corpus de análise é exposto. Para isso, sugerimos aos/às intérpretes visuais que recorram a duas ações analíticas distintas, cuja ordem pode ser alterada caso for necessário: a apresentação visual e verbal das imagens selecionadas chamando a atenção para representações específicas.

A apresentação visual das imagens selecionadas tem por objetivo socializá-las com outros indivíduos interessados nesse exercício de investigação visual crítica e inventiva. Em concordância com Hernández (2007, p. 83) que sugere que "[...] de início, não se deve trabalhar em torno de apenas uma representação visual, ainda que se possa partir de um único exemplo", recomendamos aos/ às intérpretes visuais que, em Percebendo, exponham mais de uma imagem, combinando-as. No caso de imagens em movimentos - como as fílmicas, cinematográficas e publicitárias -, a combinação de várias cenas ou frames pode favorecer aspectos narrativos, sugerindo a construção e a linearidade de uma história; no caso de artefatos visuais estáticos - como fotografias, pinturas e ilustrações - a combinação de várias imagens oportuniza o debate, a comparação e o estabelecimento de relações entre elas e sobre os estereótipos que elas reforçam ou não. 
Quanto à forma verbal, a apresentação do corpus de análise pode ser feita com informações quanto à procedência das imagens, às narrativas que elas sugerem e até mesmo mediante a uma descrição visual - procedimento a partir do qual os aspectos formais da composição são enfatizados não como objetivo em si, mas como estratégia para que nos atentemos aos detalhes que em análises superficiais poderiam passar despercebidos - quando examinamos, vasculhamos e adjetivamos os artefatos visuais buscando denunciar e transformar o olhar ensinado pela cultura da mídia, ao qual Susana Rangel Vieira da Cunha (2008, p. 121) se refere como um olhar viciado e "[...] consumidor de qualquer coisa, faminto, veloz, navegante, que não fixa detalhes, não vasculha, não discrimina". Por isso, como exercício de sistematização e de registro do que foi percebido visualmente, em Percebendo, podemos relatar a configuração das imagens, descrevendo-as.

Nesse ponto, todavia, é preciso evidenciar que as ações analíticas de Percebendo não são somente descritivas, já que narram acontecimentos e caracterizações, destacando-os como se os preparassem para a análise. Percebendo, portanto, favorece os exercícios de investigações visuais críticas e inventivas, pois, enquanto socializa as imagens selecionadas, as descreve e orienta os olhares a perceber os elementos que serão problematizados e fundamentados nas próximas etapas do PROVOQUE.

Mais do que oferecer respostas tomadas de certeza ou de descrever aquilo que é aparente, outros movimentos analíticos caracterizam as investigações elaboradas no bojo dos Estudos da Cultura Visual, tais como formular perguntas que demonstrem curiosidade e que estranhem aquilo que é tido como natural. Por meio da elaboração de perguntas, a terceira etapa do PROVOQUE, denominada Estranhando, enfatiza a ideia de que os indivíduos interagem com as imagens e podem questionar e ressignificar as mensagens que lhes são apresentadas visualmente. Concordamos com Silva (2006, p. 19-20) quando diz que, "“[...] os materiais existentes, as matérias significantes vistas como produtos, como coisas, não estão aí apenas para ser contempladas ou para ser simplesmente recebidas, aceitas e passivamente consumidas. A cultura nunca é apenas consumo passivo".

Pensando em orientar a elaboração e o compartilhamento das significações feitas pelos/as intérpretes visuais, sistematicamente, em Estranhando, as ações analíticas são formular e lançar perguntas capazes de problematizar as imagens investigadas. Por meio delas, os/as intérpretes visuais podem estranhar os estereótipos reincidentes e suspeitar daquilo que é apresentado como natural ou como única possibilidade. "Introduzir a suspeita é algo que se torna necessário como tática" analítica nas investigações sobre a Cultura Visual (HERNÁNDEZ, 2007, p. 86). Por meio dessa suspeita, é possível verificar que determinados sujeitos, corpos, gêneros, sexualidades, raças, etnias e profissões são valoriza- 
dos e evidenciados, ao passo que outros são desqualificados em estereótipos ou até mesmo invisibilizados. Artefatos da Cultura Visual, tais como filmes, propagandas, novelas e desenhos animados carregam e valorizam identidades específicas e tendem "[...] a não reconhecer as diferenças étnicas, de gênero, de diversas origens regionais e comunitárias ou a não colocá-las em evidência", como anuncia Vera Maria Candau (2010, p. 27-28).

Denominada Dialogando, a quarta etapa do PROVOQUE propõe que os questionamentos levantados na etapa anterior sejam respondidos, ainda que provisoriamente. Essa etapa opera como um convite para "olhar novamente" e buscar meios para transformar e ampliar as maneiras como os/as intérpretes visuais significam as imagens. Nesse sentido, as ações analíticas orientadas em Dialogando envolvem a pesquisa para a fundamentação das investigações visuais críticas e inventivas.

Para a sua realização, sugerimos aos/às intérpretes visuais que, por meio de exercícios de pesquisa, confrontem os estereótipos identificados nas imagens com teorias, conceitos, dados, livros, documentos, reportagens, artigos, dissertações, teses ou outras produções que versem sobre a temática e que possibilitem evidenciar as relações de poder que atravessam a produção visual. Em outras pesquisas, por exemplo, imagens cinematográficas que valorizam masculinidades específicas, foram conflitadas por nós com estudos que debatem sobre a heteronormatividade; sobre a ditadura do corpo magro e jovem; sobre a homofobia; e sobre a maneira como o machismo atinge e oprime certas expressões de masculinidade consideradas não hegemônicas (BALISCEI, 2018; BALISCEI; CALSA, 2019).

Nessa etapa, o diálogo também pode ser estabelecido com outras imagens que contribuam para sua desestabilização do estereótipo analisado. Sendo assim, tendo investigado imagens estereotipadas de masculinidades, por exemplo, pode-se buscar representações que dão ênfase a diferentes expressões de masculinidades, com corpos, medidas, cores, pesos, sexualidades e comportamentos que possam promover fissura ao estereótipo, como demonstrado em um dos estudos (BALISCEI, 2018). Neste caso, por explorar diferentes representações, a etapa Dialogando permite que o repertório dos/as intérpretes visuais seja desequilibrado e, principalmente, ampliado, quer seja pela fundamentação teórica ou pela soma de outras imagens.

Por fim, em Compartilhando, quinta e última etapa desse conjunto de procedimentos elaborado por nós, a ação analítica se concretiza na socialização das vivências proporcionadas pelo PROVOQUE. Concordamos com Imanol Aguirre (2014, p. 251) em que o ato de compartilhar o que fora produzido “[...] contém também, em si mesmo, um ato de aprendizagem, tanto para quem obtém uma resposta ao que mostra quanto para quem observa o produzido por outros, 
e extrai disso ensinamentos para suas próprias produções futuras". Pensando nisso, como estratégia de partilha entre os indivíduos, as investigações visuais críticas e inventivas podem ser socializadas de diversas formas e, inclusive, repercutir outras ações, tais como produções artísticas, cursos e oficinas de análise de imagens, rodas de conversa, exposições das imagens investigadas, planos de aula, apresentações em eventos científicos, artigos, portfólios, cartazes e painéis coletivos, relatos de experiências, etc.

Tendo apresentado e explicado as cinco etapas que configuram o PROVOQUE, na Tabela 1, sistematizamos cada uma delas de modo a destacar: a) um conjunto de verbos que indica as ações específicas a que orientam; b) suas sínteses; e c) perguntas que essas etapas auxiliam a responder.

TABELA 1 - PROVOQUE: Problematizando Visualidades e Questionando Estereótipos

\begin{tabular}{|c|c|c|c|}
\hline Etapas & Verbos/Ações & Síntese & Perguntas \\
\hline Flertando & $\begin{array}{l}\text { Buscar; } \\
\text { Escolher; } \\
\text { Reunir; } \\
\text { Justificar; }\end{array}$ & $\begin{array}{l}\text { 1) Compor o corpus de } \\
\text { análise; } \\
\text { 2) Expor os critérios } \\
\text { adotados para a seleção; }\end{array}$ & $\begin{array}{l}\text { É interessante e necessário } \\
\text { analisar quais imagens? } \\
\text { Por quê? }\end{array}$ \\
\hline Percebendo & $\begin{array}{l}\text { Mostrar; } \\
\text { Narrar; } \\
\text { Analisar; } \\
\text { Interpretar; }\end{array}$ & $\begin{array}{l}\text { 1) Apresentar visualmente } \\
\text { e verbalmente as imagens } \\
\text { selecionadas; } \\
\text { 2) Chamar atenção para } \\
\text { representações específicas, } \\
\text { preparando-as para a análise; }\end{array}$ & $\begin{array}{l}\text { Quais imagens foram } \\
\text { selecionadas? Como } \\
\text { elas são compostas? Que } \\
\text { histórias contam? }\end{array}$ \\
\hline Estranhando & $\begin{array}{l}\text { Questionar; } \\
\text { Incomodar (-se); } \\
\text { Suspeitar; } \\
\text { Denunciar; }\end{array}$ & $\begin{array}{l}\text { 1) Formular; e 2) lançar } \\
\text { perguntas que problematizem } \\
\text { os estereótipos oferecidos } \\
\text { pelas/nas imagens; }\end{array}$ & $\begin{array}{l}\text { A quem essas imagens } \\
\text { (des)favorecem? Como } \\
\text { representam a mim e ao/à } \\
\text { outro/a? }\end{array}$ \\
\hline Dialogando & $\begin{array}{l}\text { Pesquisar; } \\
\text { Desestabilizar; } \\
\text { Comparar } \\
\text { Relacionar; }\end{array}$ & $\begin{array}{l}\text { 1) Promover diálogos, } \\
\text { por exemplo, com textos } \\
\text { científicos e com outras } \\
\text { imagens; }\end{array}$ & $\begin{array}{l}\text { Como a produção } \\
\text { científica analisa esse } \\
\text { tema? Quais imagens são } \\
\text { diferentes daquelas que } \\
\text { compõem o corpus de } \\
\text { análise? }\end{array}$ \\
\hline Compartilhando & $\begin{array}{l}\text { Divulgar; } \\
\text { Oferecer; } \\
\text { Trocar; } \\
\text { Produzir. }\end{array}$ & $\begin{array}{l}\text { 1) Socializar as vivências } \\
\text { proporcionadas pelo } \\
\text { PROVOQUE }\end{array}$ & $\begin{array}{l}\text { Como é possível divulgar } \\
\text { os conhecimentos } \\
\text { construídos no } \\
\text { PROVOQUE? }\end{array}$ \\
\hline
\end{tabular}

FONTE: Elaboração nossa (2019). 


\section{Considerações}

Juntas ou separadas, as cinco etapas do PROVOQUE atuam como procedimentos que orientam a investigação visual crítica e inventiva e sugerem ações analíticas específicas para que possamos desenvolver e sensibilizar o olhar. Assim como Eduardo Kovadloff - o pai do menino que, sozinho, não conseguia ver o mar, conforme apresentado na epígrafe deste artigo -, muitos/as adultos e adultas podem ser convidados/as ou convocados/as a ensinar o/a outro/a a olhar os artefatos que integram as visualidades contemporâneas. Interpretamos que, quando diz "Pai, me ensina a olhar [o mar]!" (GALEANO, 2016, p. 15), o menino expressa a necessidade e a importância da mediação de um/a adulto/a cuja percepção visual, por hipótese, é mais elaborada do que a da criança e, por isso, pode oferecer-lhe estratégias e conhecimentos para interpretar os artefatos visuais que o rodeia.

Frases como "Pai, me ensinar a olhar o mar?", "Mãe, o que você achou desse filme?", "Professor, qual é o seu artista favorito?", "Professora, por que você selecionou essas imagens para a aula?", "Colega, qual dessas camisas você prefere?" e "O que você achou dessa minha foto?" demonstram que o nosso olhar é construído e (trans)formado pelo olhar do/a outro/a. Nesse sentido, as interpretações visuais críticas e inventivas realizadas por pesquisadores/as, professores/as e demais intérpretes visuais precisam ser complexas, múltiplas e flexíveis - já que seus olhares operam como referências para que outros indivíduos também aprendam a olhar o mar e tantas outras imagens como orientamos na criação e apresentação PROVOQUE.

É importante ressaltar que, ainda que organizado linearmente, em uma estrutura composta por ações específicas e orientadas, o PROVOQUE - como qualquer outra proposta metodológica elaborada no bojo dos Estudos da Cultura Visual - não deve ser recebido de maneira rígida, intocável, prescritiva e muito menos terminada. Ao contrário disso, os movimentos analíticos que impulsionamos atuam como um ponto de partida, como um lugar de encontro ou, melhor, como marco inicial de uma viagem cujas rotas, e até mesmo o destino, não foram determinados por nós e, quiçá, muito provavelmente, precisem de palpites, opiniões e xeretices de outros/as intérpretes visuais para começarem a ser (re)pensados.

Nessa analogia em que o PROVOQUE é comparado a uma viagem passível de modificações e, principalmente, reinvenções, queremos ressaltar o caráter transitório, compartilhado e flexível do conjunto de procedimentos analíticos que aqui elaboramos e experimentamos. O PROVOQUE é resultado dos caminhos que trilhamos em nosso exercício com a docência e com a pesquisa. É de se esperar, portanto, que um/a outro/a viajante com preocupações semelhantes ou 
diferentes das nossas prefira outros trajetos; invente seus próprios caminhos; interrompa a viagem para conhecer pontos turísticos locais; descubra atalhos que não conhecemos; desvie de nossas pegadas; ou, quem sabe - o que também seria agradável -, pegue carona conosco e decida por nos fazer companhia.

\section{REFERÊNCIAS}

AGUIRRE, Imanol. Entornos da aprendizagem entre jovens produtores de Cultura Visual: traços e características. In: MARTINS, Raimundo; TOURINHO, Irene (Orgs.). Pedagogias culturais. Santa Maria: Ed. Da UFSM, 2014, p. 175-203.

ARNHEIM, Rudolf. Arte e percepção visual: uma psicologia da visão criadora. São Paulo: Edusp/Pioneira, 1989.

BALISCEI, João Paulo. Vilões, heróis e coadjuvantes: um estudo sobre Masculinidades, Ensino de Arte e Pedagogias Disney. 2018. Tese (Doutorado) - Universidade Estadual de Maringá. Maringá, 2018.

BALISCEI, João Paulo; ACCORSI, Fernanda Amorim; TERUYA, Teresa Kazuko. Problematizando "Toda forma de amor": a visibilidade de grupos minoritários na publicidade de O Boticário. Revista Educação Unisinos, São Leopoldo, v. 21, n. 1, p. 111-121, jan./ abr. 2017. Disponível em: http://revistas.unisinos.br/index.php/educacao/article/view/ edu.2017.211.12/5859. Acesso em: 21 abr. 2017.

BALISCEI, João Paulo; CALSA, Geiva Carolina. O Bom, o Abjeto e o Cômico: construção visual das masculinidades na animação Aladdin (1992). Revista Gênero, Niterói, v. 19, p. 184-203, 2019. Disponível em: http://www.revistagenero.uff.br/index.php/ revistagenero/article/view/1195. Acesso em: 10 fev. 2019.

BALISCEI, João Paulo; SILVA, Carolina Vendrame da; CALSA, Geiva Carolina. Feminismos, Imagens e Educação: análise visual das representações femininas nas capas dos cadernos universitários da marca Tilibra. Revista Textura, Canoas, v. 20, n. 42, p. 244-278, jan./abr. 2018. Disponível em: http://www.periodicos.ulbra.br/index.php/txra/ article/view/3219/2779. Acesso em: 19 fev. 2018.

BARBOSA, Ana Mae. Tópicos Utópicos. Belo Horizonte: C/Arte, 1998.

CANDAU, Vera Maria. Multiculturalismo e educação: desafios para a prática pedagógica. In: MOREIRA, Antonio Flávio; CANDAU, Vera Maria (Orgs.). Multiculturalismo: diferenças culturais e práticas pedagógicas. 4. ed. Petrópolis, RJ: Vozes, 2010, p. 13-37. CHARRÉU, Leonardo. Cultura Visual: rupturas com inércias e ignorâncias curriculares. In: MARTINS, Raimundo; TOURINHO, Irene (Orgs.). Educação da Cultura Visual: conceitos e contextos. Santa Maria: Ed. da UFSM, 2011, p. 113-128. 
CUNHA, Susana Rangel Vieira da. Cultura Visual e Infância. In: REUNIÃO DA ASSOCIAÇÃO NACIONAL DE PÓS-GRADUAÇÃO E PESQUISA EM EDUCAÇÃO - ANPED, 31., 2008, Caxambu. Constituição Brasileira, Direitos Humanos e Educação. Rio de Janeiro: Associação Nacional de Pesquisadores em Educação, 2008, p. 102-132. Disponível em: http://www.ufrgs.br/faced/pesquisa/gein/artigos/Cultura\%20visual\%20 e\%20infancia.pdf. Acesso em: 10 jan. 2016.

DONDIS, Donis A. Sintaxe da linguagem visual. São Paulo: Martins Fontes, 1997.

GALEANO, Eduardo. O livro dos abraços. Porto Alegre: L\&PM, 2016.

HERNÁNDEZ, Fernando. Catadores da cultura visual: transformando fragmentos em nova narrativa educacional. Tradução de Ana Duarte. Porto Alegre: Mediação, 2007.

MARTINS, Raimundo; TOURINHO, Irene. Circunstâncias e Ingerências da Cultura Visual. In: MARTINS, Raimundo; TOURINHO, Irene (Orgs.). Educação da cultura visual: conceitos e contextos. Santa Maria: Ed. da UFSM, 2011, p. 51-68.

MOREIRA, Ana Angélica Albano. O espaço do desenho: a educação do educador. São Paulo: Edições Loyola, 2008.

OTT, Robert William. Ensinando crítica nos museus. In: BARBOSA. Ana Mae (Org.) Arte-educação: leituras no subsolo. São Paulo: Cortez, 2011, p. 113-141.

PEREIRA, Alexandre Adalberto. Estereótipos desenhados, identidades projetadas. In: MARTINS, Raimundo; TOURINHO, Irene (Orgs.). Cultura Visual e Infância: quando as imagens invadem a escola. Santa Maria: Ed. da UFSM, 2010, p. 209-226.

PILLAR, Analice Dutra. Leitura e Releitura. In: PILLAR, Analice Dutra (Org.). A educação do olhar no ensino das Artes. Porto Alegre: Mediação, 2011, p. 9-22.

SANTAELLA, Lucia. Leitura de imagens. São Paulo: Editora Melhoramentos, 2012.

SARDELICH, Maria Emilia. Leitura de imagens, Cultura Visual e prática educativa. Cadernos de Pesquisa, São Luís, v. 36, n. 128, p. 451-472, maio/ago. 2006. Disponível em: http://www.scielo.br/pdf/cp/v36n128/v36n128a09.pdf. Acesso em: 29 abr. 2016.

SILVA, Tomaz Tadeu da. O currículo como fetiche: a poética e a política do texto curricular. 1. ed. Belo Horizonte: Autêntica, 2006.

STEINBERG, Shirley R.; KINCHELOE, Joe. Sem segredos: cultura infantil, saturação de informações e infância pós-moderna. In: STEINBERG, Shirley R.; KINCHELOE, Joe (Orgs.). Cultura infantil: a construção corporativa da infância. Tradução de George Eduardo Japiassú Bricio. Rio de Janeiro: Civilização Brasileira, 2001. p. 9-52.

VIANNA, Maria Letícia Rauen. Desenhando com todos os lados do cérebro: possibilidades para transformação das imagens escolares. Curitiba: Ibpex, 2010.

Texto recebido em 06/04/2019.

Texto aprovado em 30/07/2019. 